\title{
RESIDUAL STRESS AND MICROSTRUCTURE IN AI-CU CLAD COMPOSITES AFTER ROTARY SWAGING AND POST-PROCESS HEAT TREATMENT
}

\author{
${ }^{1}$ Radim KOCICH, ${ }^{2}$ Lenka KUNČICKÁ \\ ${ }^{1}$ VSB - Technical University of Ostrava, Ostrava, Czech Republic, EU, radim.kocich@vsb.cz \\ 2Institute of Physics of Materials, Czech Academy of Sciences, Czech Republic, EU, kuncicka@ipm.cz \\ https://doi.org/10.37904/metal.2019.740
}

\begin{abstract}
Copper and aluminum are both widely applicable in a variety of industrial and commercial branches, from automotive to electrotechnics and laminated materials and clad composites are innovative and perspective solutions for various applications. This study deals with the investigation of structure development via internal stress analyses, grains size observation, and residual stress analyses within Al-Cu clad composites rotary swaged at room temperature and at $250{ }^{\circ} \mathrm{C}$ by optical and electron microscopy, EBSD analyses and microhardness measurements. The swaged composites were also subjected to post-process heat treatment annealing at $350{ }^{\circ} \mathrm{C}$ for 30 minutes. The results showed that intermetallic phases developed at the interfaces especially when subjected to higher temperatures (warm swaging and annealing). On the other hand, these treatments resulted in a significant decrease in the residual stress, which was also influenced substantially by sub-structure development (grain refinement). The analyses were supplemented with microhardness measurements, the results of which were in accordance with the results of substructure development.
\end{abstract}

Keywords: Clad composite, residual stress, scanning electron microscopy, EBSD, structure

\section{INTRODUCTION}

The research and development of progressive technologies and modern equipment has given birth to a variety of new innovative metal materials, such as novel laser and plasma melted alloys [1,2], pseudo-alloys fabricated via powder metallurgy [3,4], high entropy alloys (HEAs) [5], also characterized as multi-principal element (MPE) alloys [6,7], functionally graded materials [8, 9], hybrid and hierarchical materials [10,11], and composites [12]. The modern composites can be of various types, the main are MMC (Metal Matrix Composites) [13] offering the advantages of the component metals (for example high electrical and thermal conductivity) while benefiting from the additions of dispersed particles or fibres to additionally increase their strength [14], and laminated and clad composites featuring several layers of various metals each one introducing characteristic properties to create their advantageous combination within the final product [15].

The metal components used for the individual composites, as well as the fabrication method, typically depend on the intended application of the final product. Among the favourable combinations of metals for modern composites are aluminum and copper, both featuring high thermal and electric conductivity. Combining Al and $\mathrm{Cu}$ can also provide several other advantages, such as low density, and lower cost comparing to monolithic $\mathrm{Cu}$. However, they are prone to form compounds when in contact, i.e. form intermetallics at the interfaces, especially at elevated temperatures. As found previously for layered Al-Cu composites [16], high-temperature post-process annealing supports the development of intermetallics. On the other hand, heat treatment also supports structure restoration and grain refinement. Also, both the metals are hardenable via various methods, from solid solution strengthening, through precipitation hardening, to work hardening [17-20]. Therefore, intensive plastic deformation provides a favourable solution for production of clad and laminated composites at low temperatures, or even under cold conditions.

Conventional (e.g. extrusion [21], rolling [22], and forging [23]), as well as non-conventional (e.g. equal channel angular pressing [24], friction stir processing [25], and rotary swaging [16]) fabrication technologies have been 
applied to manufacture composites. The primary focus of this study was to prepare Al-Cu wires with promising application e.g. for energy transfer via rotary swaging (RS) at room as well as elevated temperature.

This report deals with the evaluation of the influence of the swaging degree and temperature on the fabricated $\mathrm{Al}-\mathrm{Cu}$ clad composites. The mutual interfaces, as well as grains refinement, local misorientations indicating internal stress and the presence of residual stress were studied via electron microscopy. The analyses were supplemented with microhardness measurements and with the results for swaged samples subjected to postprocess annealing at $350^{\circ} \mathrm{C}$ for 30 minutes.

\section{EXPERIMENTAL WORKS}

The originally used materials were commercially pure (CP) copper (with $0.002 \mathrm{wt} \% \mathrm{O}, 0.015 \mathrm{wt} \% \mathrm{P}, 0.002$ wt $\% \mathrm{Zn}$ ), and CP electro-conductive aluminum (with $0.20 \mathrm{wt} \% \mathrm{Si}, 0.25 \mathrm{wt} \% \mathrm{Fe}, 0.05 \mathrm{wt} \% \mathrm{Cu}$ ). The circular long rods/wires of the Al-Cu clad composites were manufactured via the RS fabrication technology, which is very favourable for production of long axisymmetric products, such as long conductors for the automotive. RS provides the products with exceptional quality surface and dimensional accuracy and, by introducing intensive plastic strain, also favourably influences the structure and properties of the final products [26].

The composites were swaged at room temperature (composite $\mathrm{A}$ ) and at $250{ }^{\circ} \mathrm{C}$ (composite $\mathrm{B}$ ) and selected samples were further annealed at $350^{\circ} \mathrm{C}$ for 30 minutes [27] in order to detect changes in the residual stress and sub-structure development. For both the swaging procedures, the original outer diameter of the aluminum workpiece was $30 \mathrm{~mm}$ and the diameters of the $\mathrm{Cu}$ wires were $3 \mathrm{~mm}$ (the design of the composite was described e.g. in [26]). The composites were swaged to the final diameter of $5 \mathrm{~mm}$ in several swaging passes. All the subsequent analyses were performed on transversal samples (taken in the direction perpendicular to composite axis).

Detailed analyses of the swaged-pieces were performed via scanning electron microscopy (SEM), a Tescan Lyra 3 FIB/SEM microscope equipped with a NordlysNano electron back-scattered diffraction (EBSD) detector was used. The scanned images were evaluated with the help of OXFORD Instruments [28] and LEM3 Laboratories [29] software. Microhardness examinations were performed using a Zeiss microhardness measuring equipment with the load of $250 \mathrm{~g}$ and load time of $10 \mathrm{~s}$; the average Al matrix values were calculated from a set of at least five values measured across the particular composite diameter (excluding the Cu wires), while the average $\mathrm{Cu}$ values were calculated from a set of values measured for all the individual wires. All the samples were prepared via grinding on SiC papers and diamond suspension polishing. For EBSD observations, the samples were finally polished electrolytically.

\section{RESULTS AND DISCUSSION}

\subsection{Microhardness}

The average microhardness measured for the Al matrix and Cu wires of $10 \mathrm{~mm}, 7.5 \mathrm{~mm}$ and $5 \mathrm{~mm}$ composites $A$ and $B$ and annealed samples are depicted in Table 1. As can be seen, the microhardness of the composite $A$ Al matrix increased with increasing imposed strain. However, the increase was more significant between the $10 \mathrm{~mm}$ and $7.5 \mathrm{~mm}$ passes (almost by $18 \%$ ), while the increase after swaging to $5 \mathrm{~mm}$ was by $\sim 8 \%$ despite the higher total swaging degree. This phenomenon can be explained by achieving the maximum work hardening ability of the matrix during the final swaging; due to the intrinsic properties of $\mathrm{Al}$ (stacking fault energy value etc. [17]), the imposed strain was primarily "consumed" by the Al matrix [15, 17]. This was also confirmed by the structure development, as discussed further. For the $10 \mathrm{~mm}$ and $7.5 \mathrm{~mm}$ composites Cu component, the trend was similar as for the $\mathrm{Al}$, however, the $\mathrm{Cu}$ hardness slightly decreased after swaging to $5 \mathrm{~mm}$.

For composite $B$, the trends for the $\mathrm{Al}$ and $\mathrm{Cu}$ components microhardness values were similar to composite $A$, but the percentual increases between the individual passes were comparable $(\sim 15 \%$ and $\sim 13 \%$, from $10 \mathrm{~mm}$ 
and $7.5 \mathrm{~mm}$ for Al, respectively). The results show that the elevated swaging temperature led to an earlier activation of the softening processes when compared to composite $A$. Primarily by this reason, composites $B$ generally exhibited slightly lower HV values than composite $A$. The applied heat treatment then resulted in a significant decrease in microhardness for both the components. The heat treatment thus evidently supported restoration processes within the structures. On the other hand, it promoted the development of intermetallic phases at the interfaces (Section 3.2) [27]. Nevertheless, the microhardness for the $5 \mathrm{~mm}$ composites Al matrix did not exhibit such a significant decrease as the Cu component. This can be attributed to a notable presence of precipitates within the Al matrix supporting work hardening $[15,27]$.

Table 1 Average microhardness for components within swaged and heat treated composites $\left({ }^{*} 350{ }^{\circ} \mathrm{C}\right)$

\begin{tabular}{|c|c|c|c|c|c|c|c|c|c|c|c|c|}
\hline Composite type & A & A & A & A $^{*}$ & A $^{*}$ & A $^{*}$ & B & B & B & B $^{*}$ & B $^{*}$ & B $^{*}$ \\
\hline Diameter (mm) & 10 & 7.5 & 5 & 10 & 7.5 & 5 & 10 & 7.5 & 5 & 10 & 7.5 & 5 \\
\hline Avg. Al HV (-) & 43.3 & 50.9 & 54.9 & 29.7 & 38.5 & 41.2 & 40.1 & 46.0 & 50.7 & 34.3 & 36.1 & 37.7 \\
\hline Avg. Cu HV (-) & 109.9 & 112.5 & 107.4 & 75.8 & 81.6 & 89.1 & 103 & 110.8 & 103.8 & 64.7 & 67.9 & 73.6 \\
\hline
\end{tabular}

\subsection{Structure analyses and grain size}

The most evident was the change in the diameters and cross-sectional shapes of the Cu wires (as shown for composite $A$ in Figure 1a). The wire diameters decreased with increasing imposed strain, but increased with increasing swaging temperature for identical composite diameters. This phenomenon was the result of the maximum strengthening ability of both the components and activation of restoration processes [15]. The wires within composite $B$ had larger diameters for identical composite diameters (not shown here) due to inter-pass softening of $\mathrm{Al}$, as a result of which the matrix had the ability to better "consume" the imposed strain. Therefore, the $\mathrm{Cu}$ wires were not influenced by the imposed strain as substantially as during swaging at $20^{\circ} \mathrm{C}$.

(a)
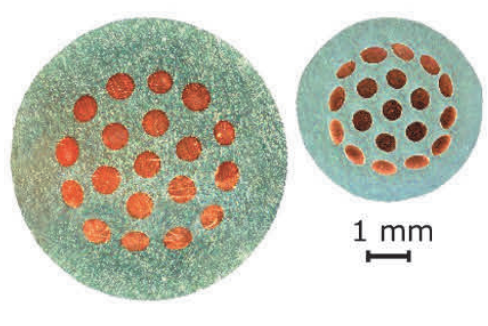

(b)

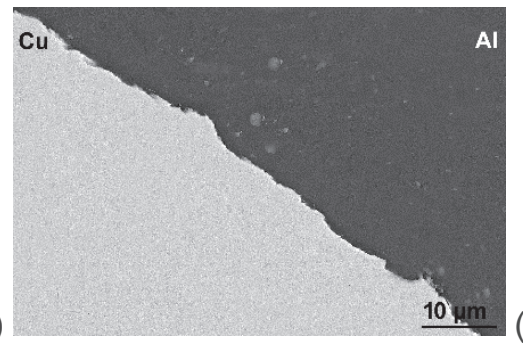

(c)

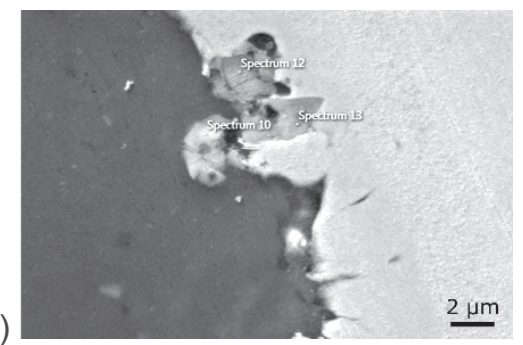

(d)

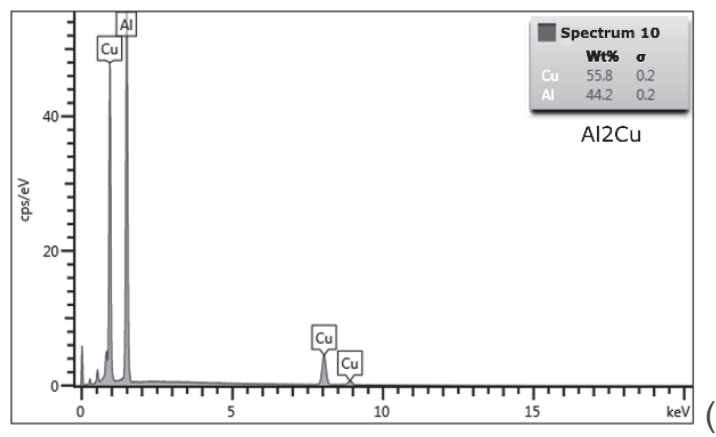

(e)

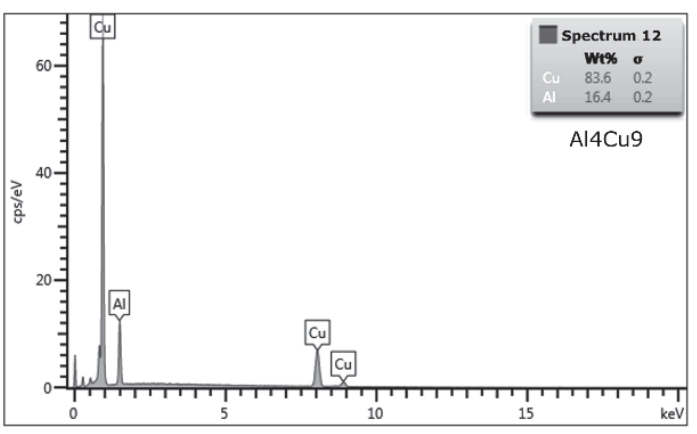

Figure 1 Cross-sectional cuts of composite A, $10 \mathrm{~mm}$ and $7.5 \mathrm{~mm}$ samples (a); Al-Cu interface of $5 \mathrm{~mm}$ composite A (b); Al-Cu interface of $5 \mathrm{~mm}$ composite B (c); EDX spectra for intermetallic phases: $\mathrm{Al}_{2} \mathrm{Cu}(\mathrm{d})$;

$$
\mathrm{Al}_{4} \mathrm{Cu}_{9}(\mathrm{e})
$$

Another issue of importance was the possible presence of intermetallic phases. No intermetallics were found in samples of composite $A$ (example in Figure 1b). However, they were detected in $5 \mathrm{~mm}$ composite $B$ 
(Figure 1c) and also in both the heat-treated composites. The observed phases were $\mathrm{Al}_{2} \mathrm{Cu}_{3}, \mathrm{Al}_{4} \mathrm{Cu}_{9}, \mathrm{AlCu}$ and $\mathrm{Al}_{2} \mathrm{Cu}$ and their mixtures depending on the examined location (examples of EDX spectra for several distinguishable phases shown in Figure 1c are depicted in Figures 1d and 1e). The intermetallics were crushed in some locations (Figure 1c), which proves their brittleness and is also in accordance with previous reports on Al-Cu composites [15]. The figures also show the presence of precipitates in the Al matrix (white spots), which supported work hardening, as discussed in the section on microhardness. According to SEMelectro dispersive spectroscopy analyses, the precipitates contained $61.9 \mathrm{wt} \% \mathrm{Al}, 37.2 \mathrm{wt} \% \mathrm{Fe}$, and $0.9 \mathrm{wt} \%$ $\mathrm{Si}$ in average.

The average grain size values for both the components within selected composites are depicted in Table 2, Figure 2 then shows the example set of EBSD scans of the copper component the data from which were further evaluated. As can be seen, the grain size between the two final swaging passes decreased slightly for composite $A \mathrm{Cu}$, however, increased for composite $B \mathrm{Cu}$. This can be attributed to the elevated swaging temperature supporting secondary recrystallization of $\mathrm{Cu}$ [18], and the fact that the final swaging reduction was little and the energy imposed to $\mathrm{Cu}$ was not sufficient for further grain refinement since the matrix "consumed" its majority (Section 3.1). For the Al, the grain sizes slightly decreased during swaging to $5 \mathrm{~mm}$ for both the composites although the HV values increased slightly - this can be attributed to the development of precipitates and particle stimulated nucleation both supporting work hardening [18]. The grain size decrease after annealing for both the composites corresponds to the HV decrease, occurring softening, and restoration of plastic properties.

(a)

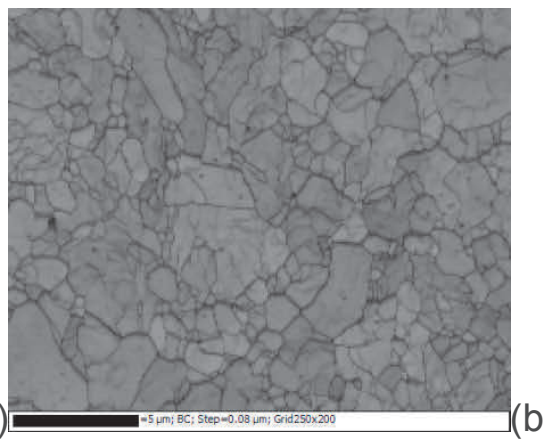

(d)

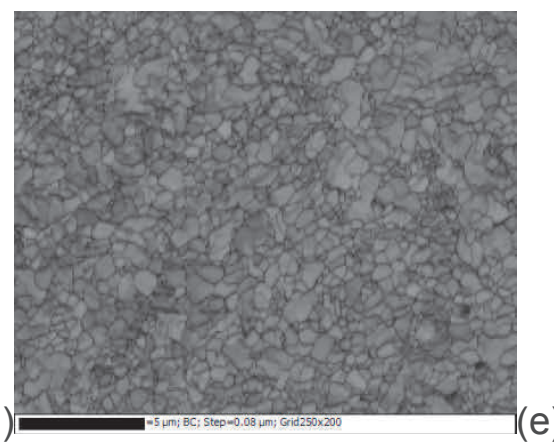

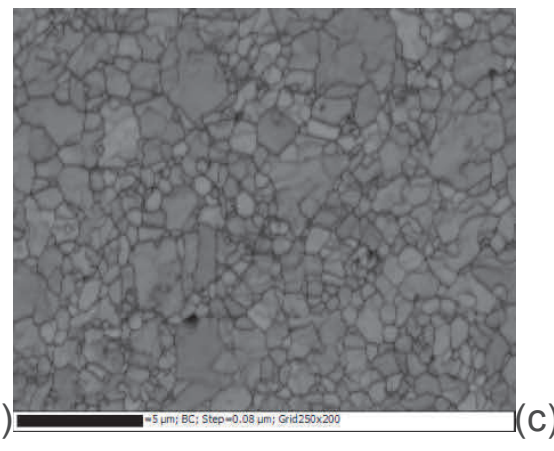
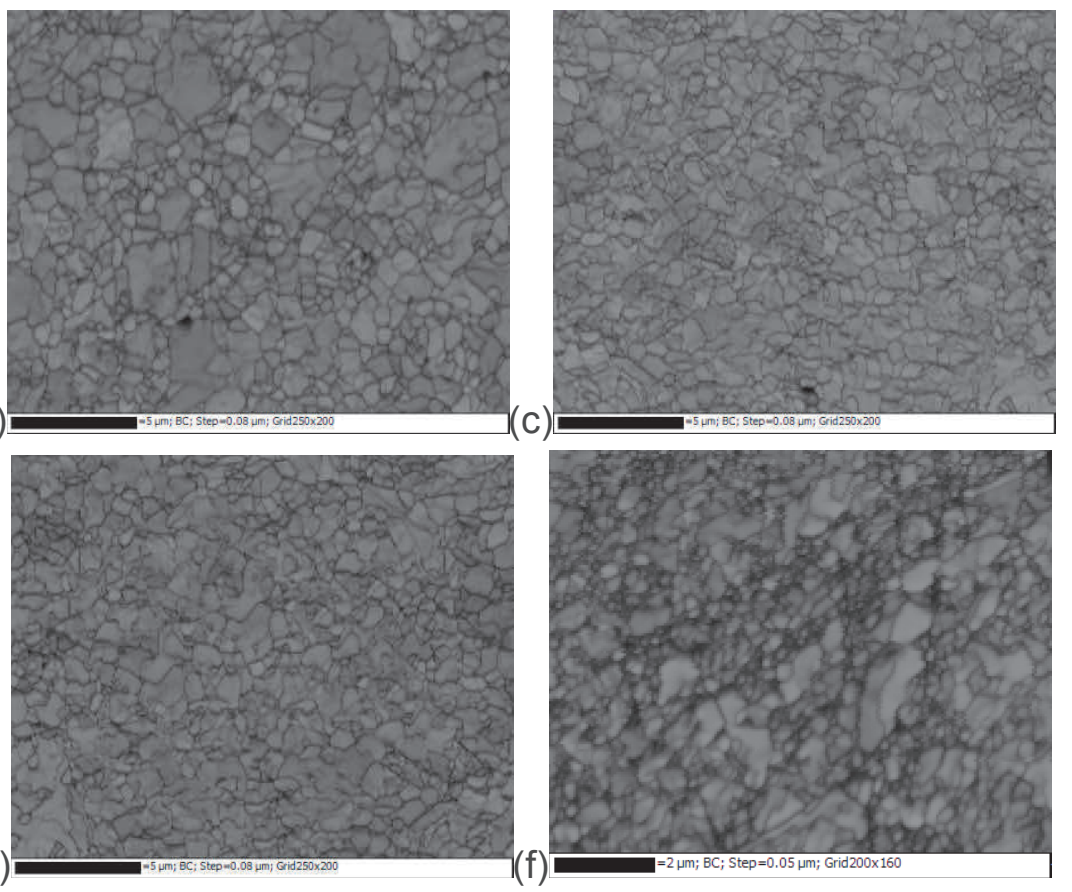

Figure 2 EBSD scans of Cu components for further evaluation: $7.5 \mathrm{~mm}$ composite $\mathrm{A}$ (a), $5 \mathrm{~mm}$ composite A (b), $5 \mathrm{~mm}$ composite $\mathrm{A}+350^{\circ} \mathrm{C}$ (c), $7.5 \mathrm{~mm}$ composite $\mathrm{B}(\mathrm{d}), 5 \mathrm{~mm}$ composite $\mathrm{B}$ (e), $5 \mathrm{~mm}$ composite $\mathrm{B}+$ $350^{\circ} \mathrm{C}(\mathrm{f})$

Table 2 Average grain size for individual components of swaged composites $\left({ }^{*} 350{ }^{\circ} \mathrm{C}\right)$

\begin{tabular}{|c|c|c|c|c|c|c|}
\hline Composite type & A & A & A $^{*}$ & B & B & B $^{*}$ \\
\hline Diameter $(\mathrm{mm})$ & 7.5 & 5 & 5 & 7.5 & 5 & 5 \\
\hline Avg. Al grain size $(\mu \mathrm{m})$ & 0.53 & 0.46 & 0.29 & 0.51 & 0.46 & 0.26 \\
\hline Avg. Cu grain size $(\mu \mathrm{m})$ & 1.06 & 1.03 & 0.63 & 0.62 & 0.91 & 0.39 \\
\hline
\end{tabular}




\subsection{Residual stress}

Severe deformation imposed especially under cold conditions leads to the development of internal stress within the structure. Such stress develops naturally during structure refinement and is usually relaxed during substructure formation [30]. However, residual stress in the structure can decrease the longevity of the final products [26]. Due to the limited space of this article, only selected scans were picked to document the structure state. The results of local misorientation analyses showed the internal stress to be present primarily at the grain boundaries after each pass, which corresponds to the occurring grain refinement. Figures $3 \mathbf{a}$ and $3 \mathbf{b}$ document the local misorientations for $\mathrm{Cu}$ of both the $7.5 \mathrm{~mm}$ composites. Evidently, the recrystallized grains featuring high-angle boundaries (strong black lines) are larger for composite $A$ and the sample is about to undergo substructure development when additional energy is imposed (i.e. during the following swaging pass). On the other hand, substructure of composite B is well-developed (supported by $250^{\circ} \mathrm{C}$ ), a large number of subgrains are forming. This also corresponds to the highest $\mathrm{HV}$ of all the composite B samples.

The analyses of internal stress within the grains then show residual stress within the samples. As can be seen in Figure 3c, the residual stress is present in the majority of the structure which corresponds to the massive substructure formation. The residual stress is further significantly relaxed after swaging to $5 \mathrm{~mm}$ for both the composites (Figures $\mathbf{3 d}$ and $\mathbf{3 e}$ ). Similarly, the post-process heat treatment induced grain refinement (the additional energy caused the composite $B$ Cu to refine significantly), as well as residual stress relaxation.

(a)
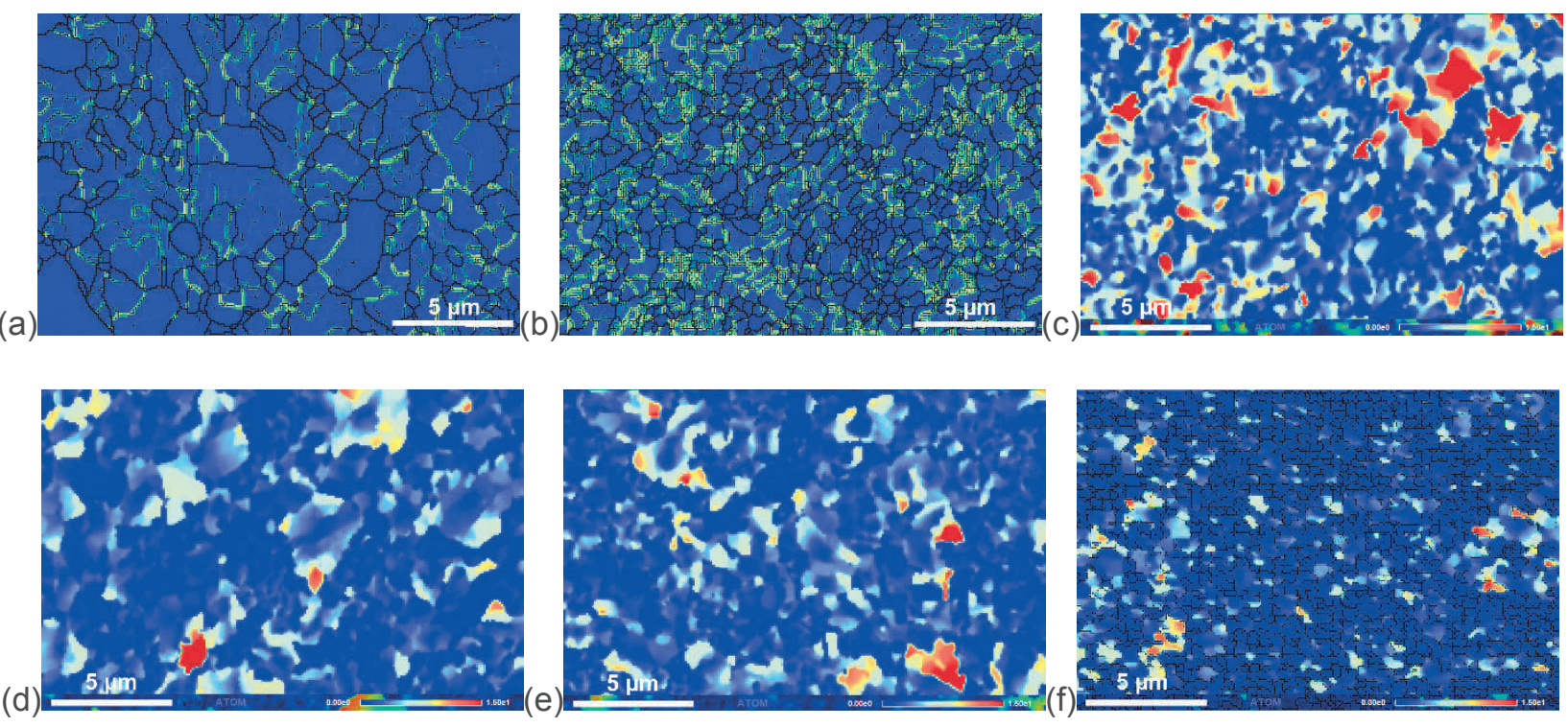

Figure 3 Local misorientations in $7.5 \mathrm{~mm}$ composite $\mathrm{A}(\mathrm{a}), 7.5 \mathrm{~mm}$ composite $\mathrm{B}$ (b). Residual stress in 7.5 $\mathrm{mm}$ composite B (c), $5 \mathrm{~mm}$ composite $\mathrm{A}(\mathrm{d}), 5 \mathrm{~mm}$ composite $\mathrm{B}$ (e), $5 \mathrm{~mm}$ composite $\mathrm{B}+350{ }^{\circ} \mathrm{C}$ (f).

\section{CONCLUSION}

The analyses showed that microhardness of both the components was generally higher for composites swaged at room temperature (RT) than at $250^{\circ} \mathrm{C}$. After swaging to $5 \mathrm{~mm}$ at RT, the Al matrix exhibited exhaustion of its work hardening ability. The grain refinement was more notable for composites swaged at $250^{\circ} \mathrm{C}$, however, the combination of elevated temperature and little final reduction ratio caused the $\mathrm{Cu}$ grains to coarsen by secondary recrystallization during swaging to $5 \mathrm{~mm}$. This effect was eliminated by subsequent heat treatment. On the other hand, heat treatment promoted the development of intermetallics, as did also the $250{ }^{\circ} \mathrm{C}$ during the final swaging pass. The presence of residual stress was not significant within both the final $5 \mathrm{~mm}$ composites due to the notable substructure development causing its relaxation, which was documented by local misorientations analyses. The post-process annealing further decreased the presence of residual stress, 
and introduced further structure refinement. Suffice to say, the $5 \mathrm{~mm} \mathrm{Al-Cu}$ composite wires were successfully fabricated via rotary swaging, the final wires had ultra-fine grained structures and did no significant presence of residual stress.

\section{ACKNOWLEDGEMENTS}

The authors acknowledge support by the GACR project No. 19-15479S.

\section{REFERENCES}

[1] SHAIK Mahammad Ali and GOLLA, Brahma Raju. Development of highly wear resistant $\mathrm{Cu}$ - Al alloys processed via powder metallurgy. Tribology International. 2019. vol. 136, pp. 127-139.

[2] LI, Guoling, HENG, Guo, LI, Li, WANG, Chongyun, ZHENG, Jie, TIAN, Wenhuai and LI, Heping. Purification of terbium by means of argon and hydrogen plasma arc melting. Journal of Alloys and Compounds. 2016. vol. 659, pp. 1-7.

[3] KOCICH, Radim, KUNČICKÁ, Lenka, DOHNALÍK, Daniel, MACHÁČKOVÁ, Adéla and ŠOFER, Michal. Cold rotary swaging of a tungsten heavy alloy. Numerical and experimental investigations. International Journal of Refractory Metals and Hard Materials. 2016. vol. 61, pp. 264-272.

[4] LIANG, Shuhua, WANG, Xianhui, WANG, Lingling, CAO, Weichan and FANG, Zhikang. Fabrication of CuW pseudo alloy by W-CuO nanopowders. Journal of Alloys and Compounds. 2012. vol. 516, pp. 161-166.

[5] WANG, Zhijun, WU, Qingfeng, ZHOU, Wenquan, FENG, He, YU, Chunyan, LIN, Deye, WANG, Jincheng and LIU, C. T. Quantitative determination of the lattice constant in high entropy alloys. Scripta Materialia. 2019. vol. 162, pp. 468-471.

[6] HUANG, Xuejun, MIAO, Jiashi and LUO, A. Lightweight AICrTiV high-entropy alloys with dual-phase microstructure via microalloying. Journal of Materials Science. 2019. vol. 54, pp. 2271-2277.

[7] COUZINIÉ, Jean Philippe and DIRRAZ, Guy. Body-centered cubic high-entropy alloys: From processing to underlying deformation mechanisms. Materials Characterization. 2019. vol. 147, pp. 533-544.

[8] WATARI, Fumio, YOKOHAMA, Atsuro, OMORI, Mamoru, HIRAI, Toshiro, KONDO, Hideomi, UO, Motohiro and KAWASKI, Takao. Biocompatibility of materials and development to functionally graded implant for bio-medical application. Composites Science and Technology. 2004. vol. 64, pp. 893-908.

[9] IQBAL, M. D. and BIRK, C. Numerical modelling of thermally induced crack propagation in functionally graded materials using the scaled boundary finite element method. In: Forschungskolloquium 2018. Schneider J., Kiziltoprak N. (Eds.), Grasellenbach, Springer Vieweg, Wiesbaden. 2018. pp. 37-38.

[10] YAN, Y. and PRIYA, S. Multiferroic magnetoelectric composites/hybrids. In Hybrid Hierarchical Compos. Mater. C.-S. Kim, C. Randow, T. Sano (Eds.), Springer International Publishing, Cham. 2015. pp. 95-160.

[11] LI, Jianyu, ZHAO, Gaozhan, WU, Shusen, HUANG, Zhiwei, LÜ, Shulin, CHEN, Qiang, LI, Fei. Preparation of hybrid particulates SiCnp and Mg2Si reinforced Al-Cu matrix composites, Materials Science and Engineering: A. 2019. vol. 751, pp. 107-114.

[12] TJONG, S. C. and MA, Zongyi. Microstructural and mechanical characteristics of in situ metal matrix composites. Material Science and Engineering R. 2000, vol. 29, pp. 49-113.

[13] BAURI, R. and YADAV, D. Metal Matrix Composites by Friction Stir Processing. Butterworth-Heinemann. 2017.

[14] KUNČICKÁ, Lenka, LOWE, Terry, DAVIS, Casey, KOCICH, Radim and POHLUDKA, Martin. Synthesis of an $\mathrm{Al} / \mathrm{Al}_{2} \mathrm{O}_{3}$ composite by severe plastic deformation. Materials Science and Engineering: A. 2015. vol. 646, pp. 234241.

[15] KOCICH, Radim, KUNČICKÁ, Lenka, MACHÁČKOVÁ, Adéla and ŠOFER, Michal. Improvement of mechanical and electrical properties of rotary swaged Al-Cu clad composites. Materials and Design. 2017. vol. 123, pp. 137146.

[16] KUNČICKÁ, Lenka and KOCICH, Radim. Deformation behaviour of Cu-Al clad composites produced by rotary swaging. In: IOP Conference Series: Materials Science and Engineering. 2018. vol. 369, p. 12029. 
[17] RUSSELL, A. and LEE, K.L. Structure-Property Relations in Nonferrous Metals. 1st ed., John Wiley \& Sons, Inc., New Jersey, 2005.

[18] VERLINDEN, B., DRICER, J., SAMAJDAR, I. and DOHERTY, R.D. Thermo-Mechanical Processing of Metallic Materials. Elsevier, Amsterdam, 2007.

[19] AMOS, A.A., AKEEM, G., EMMANUEL, F.O., AJIBADE, O.J. and OLADAYO, O. The Effect of Thermomechanical Ageing of Aluminum-Copper Alloy (MATLAB Approach). In Springer, Cham, 2003. pp. 481-486.

[20] HAAS, M. D. and HOSSON, J. T. M. D. On the effects of thermomechanical processing on failure mode in precipitation-hardened aluminum alloys. J. Materials Science. 2002. vol. 37, pp. 5065-5073.

[21] LUO, Jun-ting, ZHAO, Shuang-jing and ZHANG, Chun-xiang. Microstructure of aluminum/copper clad composite fabricated by casting-cold extrusion forming. Journal of Central South University of Technology. 2011. vol. 18, pp. 1013-1017

[22] MARQUÉZ, Jose, LEIVA, Daniel, FLORIANO, Ricardo, SOYAMA, Juliano, SILVA, Wagner, ISHIKAWA, Tomaz, KIMINAMI, Claudio and BOTTA, Walter. Hydrogen storage in MgH2LaNi5 composites prepared by cold rolling under inert atmosphere. International Journal of Hydrogen Energy. 2018. vol. 43, pp. 13348-13355.

[23] PUROHIT, Rajesh, QURESHI, M. and KUMAR, Bhrant. Effect of forging on aluminum matrix nano composites: A review. Materials Today: Proceedings. 2017. vol. 4, pp. 5357-5360.

[24] BHARATH, A., SUNDEEP, A., SHARAN, A., REDDY, A. and PHANIBHUSHANA, M. Characterisation of aluminum metal matrix hybrid composites subjected to equal channel angular pressing. Materials Today: Proceedings. 2018. vol. 5, pp. 25396-25403.

[25] AURORA, H., SINGH, H. and DHINDAW, B. Composite fabrication using friction stir processing - A review. International Journal of Advanced Manufacturing Technology. 2012. vol. 61, pp. 1043-1055.

[26] KUNČICKÁ, Lenka, KOCICH, Radim, STRUNZ, Pavel, MACHÁČKOVÁ, Adéla. Texture and residual stress within rotary swaged Cu/Al clad composites. Materials Letters 2018. vol. 230, pp. 88-91.

[27] KOCICH, Radim, KUNČICKÁ, Lenka, DAVIS, Casey, LOWE, Terry, SZURMAN, Ivo, MACHÁČKOVÁ, Adéla. Deformation behavior of multilayered Al-Cu clad composite during cold-swaging. Materials and Design. 2016. vol. 90, pp. 379-388.

[28] Providing leading-edge tools for SEM, TEM \&FIB - Nanoanalysis. Oxford Instruments. 2018.

[29] BEAUSIR, B. and FUNDENBERGER J.J. Analysis Tools for Electron and X-ray Diffraction. ATEX - software. 2017. Avaliable from: www.atex-software.eu.

[30] HUMHERYS, F. J. and HATHERLY, M. Recrystallization and Related Annealing Phenomena. 2nd ed., Elsevier Ltd, Oxford, 2004. Avaliable from: https://www.sciencedirect.com/book/9780080441641. 